\title{
Politics and community-based research: Perspectives from Yeoville Studio, Johannesburg
}

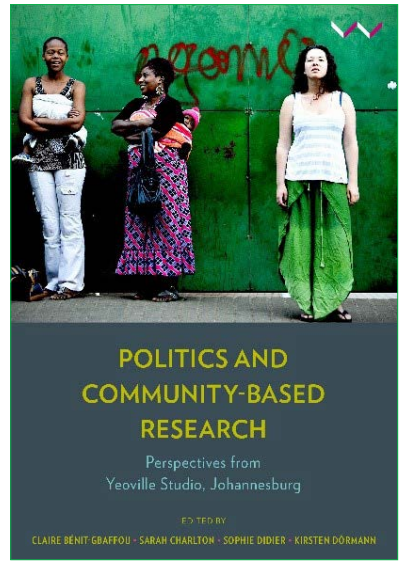

Editors: Claire Bénit-Gbaffou, Kirsten Dörmann, Sarah Charlton \& Sophie Didier

Published by: Wits University Press, October 2019

\section{Review by: Selna Cornelius}

DOI: http://dx.doi.org/10.18820/2415-0495/trp76i1.8

Honest, self-examining, critical literature on community-based research is a rare commodity. A considerable portion of the current literature on community-based research succumbs to the temptation of romanticising the 'community' and the poor, in the process purposefully or inadvertently avoiding the complexities of community politics. Illuminating 'community politics in engaged research', this book is a voice for participatory research, providing constructive criticism of service learning, while advocating for responsible and sensitive research.

Carefully selected for its contested and diverse community, the Johannesburg inner-city neighbourhood of Yeoville provides the backdrop for this twoyear community-based research initiative by the School of Architecture and Planning at the University of the Witwatersrand (Wits). Aptly named the Yeoville Studio, the research initiative comprised various short-term projects and studies, involving a multidisciplinary field of Wits academics, roughly 150 under- and postgraduate students, as well as three civil society organisations. Drawing on themes of 'public space and its management', 'diversity and the quest for social cohesion', 'housing as a public issue', and 'local memories and identity' underpinning the research, the book offers a compelling critical reflection of the Yeoville Studio. Masterfully dovetailing investigative theoretical chapters with an assemblage of vignettes describing the spaces and lives of Yeoville residents, the book provides fresh insight into the intricacies of politics involved in community-based research.

Distinguishing itself from other publications on community-based research, this book is filled with the voices of the community, leaving a personal imprint on the research and providing a powerful testimony to the use of local memories, narratives and visual illustration. It is an ode to the significance of applying in-depth, single-case study research, humbling in its honesty in the portrayal of the lessons learnt by the researchers involved. It is an important work on engaged research, openly and courageously discussing the politics of knowledge, uncertainty and ethical challenges in participatory research.

The candid way in which the book confronts politics in communitybased research as well as the raw honesty of this publication will resonate with a multidisciplinary audience of scholars, practitioners and policymakers. This book will challenge and deepen arguments on community-based research and is a must-read for a readership interested in engaged research, service learning, community participation, and urban politics. 